\title{
Epidemiology and aetiology of dialysis-treated end-stage kidney disease in Libya
}

Wiam A Alashek ${ }^{1,3}$, Christopher W Mclntyre ${ }^{1,2,3}$ and Maarten W Taal ${ }^{2,3^{*}}$

\begin{abstract}
Background: The extent and the distribution of end stage kidney disease (ESKD) in Libya have not been reported despite provision of dialysis over 4 decades. This study aimed to develop the first comprehensive description of the epidemiology of dialysis-treated ESKD in Libya.

Methods: Structured demographic and clinical data were obtained regarding all adult patients treated at all maintenance dialysis facilities ( $n=39$ ) in Libya from May to September 2009. Subsequently data were collected prospectively on all new patients who started dialysis from September 2009 to August 2010. Population estimates were obtained from the Libyan national statistics department. The age and gender breakdown of the population in each region was obtained from mid-2009 population estimates based on 2006 census data.

Results: The prevalence of dialysis-treated ESKD was 624 per million population (pmp). 85\% of prevalent patients were aged $<65$ years and $58 \%$ were male. The prevalence of ESKD varied considerably with age with a peak at 55-64 years (2475 pmp for males; $2197 \mathrm{pmp}$ for females). The annual incidence rate was $282 \mathrm{pmp}$ with some regional variation and a substantially higher rate in the South (617 pmp). The most common cause of ESKD among prevalent and incident patients was diabetes. Other important causes were glomerulonephritis, hypertensive nephropathy and congenital or hereditary diseases.
\end{abstract}

Conclusions: Libya has a relatively high prevalence and incidence of dialysis-treated ESKD. As the country prepares to redevelop its healthcare system it is hoped that these data will guide strategies for the prevention of CKD and planning for the provision of renal replacement therapy.

Keywords: Dialysis, Epidemiology, ESKD, Incidence, Libya, Prevalence

\section{Background}

End-stage kidney disease (ESKD) is highly prevalent globally. It has become a major public health problem and is associated with considerable co-morbidity and mortality. Maintenance dialysis therapy is the commonest mode of renal replacement therapy and demand for this service is increasing progressively worldwide.

Libya is a sparsely populated medium-developed country but it has a high prevalence of risk factors for chronic kidney disease (CKD) such as diabetes, hypertension and obesity [1-4]. Societal, economic and environmental transformation have contributed to people tending to adopt a sedentary life [5]. Attention paid by

\footnotetext{
* Correspondence: Maarten.Taal@derbyhospitals.nhs.uk

${ }^{2}$ Department of Renal Medicine, Derby Hospitals NHS Foundation Trust, Derby, UK

${ }^{3}$ Royal Derby Hospital, Uttoxeter Road, Derby DE22 3NE, UK

Full list of author information is available at the end of the article
}

the primary health care systems to combat the rising epidemic of chronic diseases has been inadequate [6]. In contrast, Libya was among the first countries in the region to establish free access to maintenance dialysis therapy for patients with ESKD [7]. Health care administrative bodies have continued to expand dialysis services in terms of geographic coverage and capacity to cope with increasing demand [7]. Kidney transplantation in Libya is limited by the lack of cadaveric donors and limited availability of suitable living-related donors $[8,9]$. Thus the majority of patients with ESKD remain dialysis dependent. Nevertheless, data regarding the epidemiology of ESKD and dialysis treatment in Libya are scarce and knowledge about the spectrum of renal diseases is very limited. The purpose of this study was to develop the first comprehensive description of the epidemiology of dialysis-treated ESKD in Libya. The study was performed prior to the recent conflict but as Libya prepares

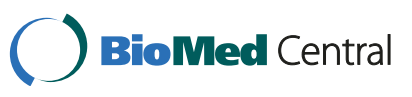


to redevelop its healthcare system these data will be vital to guide strategies for the prevention of CKD and planning for the provision of renal replacement therapy.

\section{Results}

\section{Prevalence of ESKD in Libya}

As shown in Table 1, the total number of adult ESKD patients undergoing maintenance dialysis therapy in Libya was 2417 in August 2009. The estimated adult population of Libya during 2009 was 3,873,000, giving a prevalence of dialysis-treated ESKD of approximately 624 per million population ( $\mathrm{pmp}$ ). The prevalence rate varied slightly by region with the highest rate of $628 \mathrm{pmp}$ in North West region, the most populated area of the country. Most prevalent patients were under 65 years of age (85\%). Female patients tended to be older than males, except in the South. Duration of dialysis was a median of 3 years and tended to be lower in females (Table 2). The majority of dialysis patients were Libyan nationals $(97.8 \%$ of prevalent and $96.6 \%$ of incident patients).

Figure 1, shows that the prevalence of dialysis-treated ESKD was higher among males versus females at all ages. Overall, males represented $58 \%$ of prevalent dialysis population. The prevalence of ESKD varied considerably with age. Prevalence rates were low in young adults but showed a steady increase with age. Prevalence rates peaked in the 55-64 year age group at $2475 \mathrm{pmp}$ for males and $2197 \mathrm{pmp}$ for females. After age 74 years there was a sharp decline in prevalence and very few patients were over 85 years. Most prevalent patients on dialysis were white ethnicity (87\%). However, ethnic distribution varied between regions with the highest black to white ratio of 1.9 to 1 in the South.

\section{Incidence of ESKD in Libya}

A total of 1093 new patients started dialysis during the 1 -year observation period, giving an incidence rate of $282 \mathrm{pmp}$. Incidence rates varied between regions with a substantially higher rate observed in the South (Table 1). In most age groups the incidence rate was higher in males

Table 1 Prevalent and Incident dialysis patient numbers and rates for Libya and its regions

\begin{tabular}{lllll}
\hline & \multicolumn{3}{c}{ Regions } & Whole \\
\cline { 2 - 3 } & $\begin{array}{l}\text { North } \\
\text { West }\end{array}$ & $\begin{array}{l}\text { North } \\
\text { East }\end{array}$ & South & \\
\hline $\begin{array}{l}\text { Number of prevalent } \\
\text { patients 2009 }\end{array}$ & 1558 & 653 & 206 & 2417 \\
\hline $\begin{array}{l}\text { Prevalence rate 2009 } \\
\text { (pmp) }\end{array}$ & 628 & 623 & 597 & 624 \\
\hline $\begin{array}{l}\text { Number of incident } \\
\text { patients 2010 }\end{array}$ & 593 & 287 & 213 & 1093 \\
\hline $\begin{array}{l}\text { Incidence rate 2010 } \\
\text { (pmp) }\end{array}$ & 239 & 274 & 617 & 282 \\
\hline
\end{tabular}

Table 2 Age, age at onset and dialysis vintage for prevalent and incident dialysis patients in Libya and its regions. Data are median and interquartile range

\begin{tabular}{|c|c|c|c|c|c|c|}
\hline & & \multicolumn{3}{|c|}{ Region } & \multirow{2}{*}{$\begin{array}{l}\text { Total/ } \\
\text { gender }\end{array}$} & \multirow[t]{2}{*}{ Total } \\
\hline & & $\begin{array}{l}\text { North } \\
\text { West } \\
(n=1558)\end{array}$ & $\begin{array}{l}\text { North } \\
\text { East } \\
(n=653)\end{array}$ & $\begin{array}{l}\text { South } \\
(n=206)\end{array}$ & & \\
\hline Age of prevalent & Male & 49 & 46 & 49 & 48 & \\
\hline patients in years & & $36-61$ & $35-59$ & $36-61.3$ & $36-61$ & 49 \\
\hline \multirow[t]{2}{*}{$(n=2417)$} & Female & 49 & 50.5 & 42.5 & 49 & $36-61$ \\
\hline & & $34-60$ & $37-61$ & $32.3-59$ & $35-61$ & \\
\hline $\begin{array}{l}\text { Age at onset } \\
\text { of dialysis }\end{array}$ & Male & 45 & 42 & 47 & 44 & \\
\hline \multirow[t]{3}{*}{$(n=2417)$} & & $31-58$ & $28-55$ & $31-59.9$ & $30-58$ & 45 \\
\hline & Female & 45 & 46 & 38 & 45 & $30-58$ \\
\hline & & $30-57$ & $31-57$ & $27-57.8$ & $30-57$ & \\
\hline $\begin{array}{l}\text { Dialysis vintage } \\
\text { in years }\end{array}$ & Male & 3 & 3 & 2 & 2.5 & \\
\hline \multirow[t]{3}{*}{$(n=2417)$} & & $1-6$ & $1-7$ & $0.1-4$ & $1-6$ & 3 \\
\hline & Female & 3 & 3 & 2 & 3 & $1-6$ \\
\hline & & $1-5$ & $1-6$ & $2-2$ & $1-6$ & \\
\hline $\begin{array}{l}\text { Age of incident } \\
\text { patients }\end{array}$ & Male & 50 & 47 & 46 & 48 & \\
\hline \multirow[t]{3}{*}{ in years $(n=1093)$} & & $37-63$ & $34-61$ & $30-57$ & $35-61$ & 49 \\
\hline & Female & 52 & 53 & 43 & 50 & $35-62$ \\
\hline & & $35-66$ & $41-64$ & $36-54$ & $36-64$ & \\
\hline
\end{tabular}

than females (Figure 2). The incidence rate increased with age until it peaked in those aged 65-74 years and decreased sharply beyond age 75 years. Incident female patients were slightly older than male patients. Most incident patients on dialysis were white (80.9\%).

\section{Aetiology of ESKD in Libya}

Information about primary kidney disease was complete for all prevalent dialysis patients but was missing in 75 (6.9\%) of incident dialysis patients. Data are shown in Tables 3 and 4. The most common cause of ESKD among prevalent and incident patients was diabetes. The frequency of different categories of pathology was similar for prevalent and incident patients. Diabetes and hypertensive nephropathy were more common as causes of ESKD in patients aged 50 years or older whereas glomerulonephritis and hereditary diseases were more common in those aged under 50 years. Autoimmune diseases accounted for only a small proportion of all ESKD and were more common among females.

\section{Discussion}

This study represents the first comprehensive description of the epidemiology of dialysis-treated ESKD in 


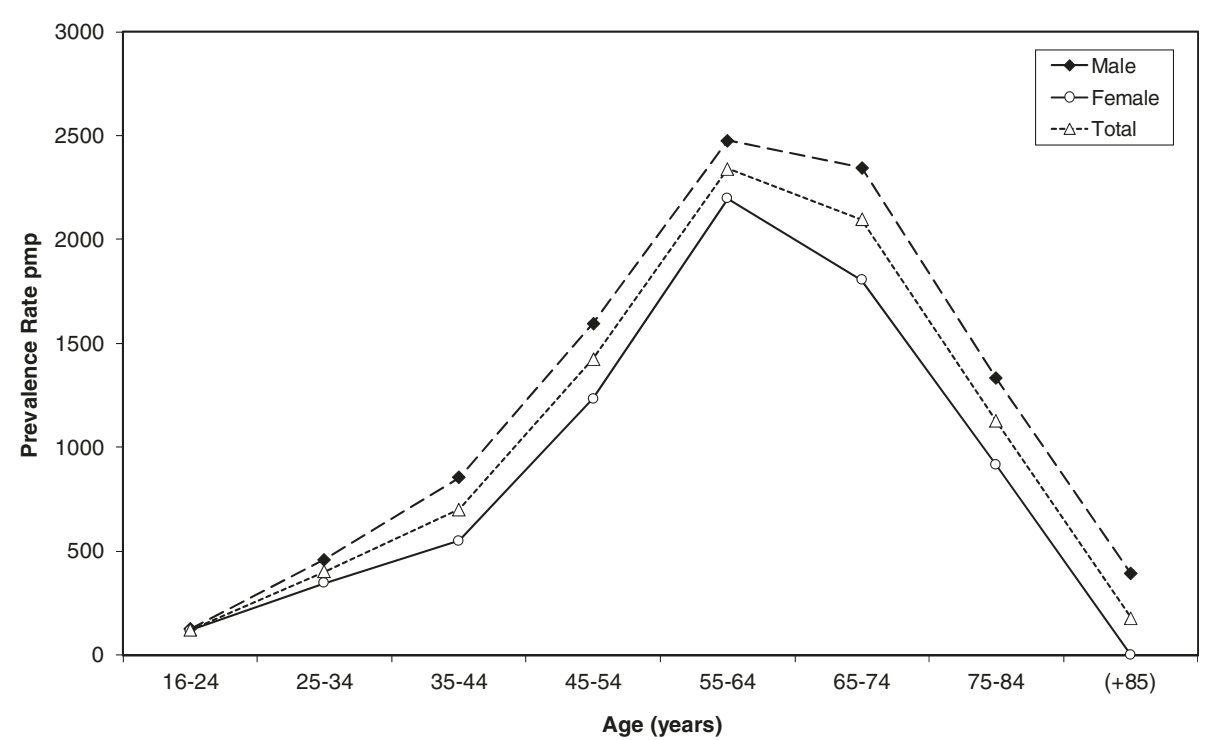

Figure 1 Prevalence rate pmp of dialysis-treated ESKD in Libya for males and females by age group.

Libya. Our study shows a prevalence rate for ESKD markedly higher than rates estimated for the Mediterranean region of 312 to 352 pmp [10,11] despite similar demographic and socioeconomic characteristics between Libya and neighbouring countries. Libya's prevalence rate is also higher than rates reported from individual countries in the region like Saudi Arabia (475 pmp) [12], El-Minia city in Egypt (208 pmp) [13], Kuwait (240 pmp) [10] and Oman (220 pmp) [10]. Reasons for the high prevalence rate in Libya might include a high prevalence of CKD in the population and limited access to renal transplantation $[8,14]$. The high incidence rate of ESKD observed in this study (282 pmp) supports the notion that CKD is an important health problem in Libya that requires urgent attention. The rate is more than double that observed in European countries such as Austria (131 pmp) [15] and Denmark (129 pmp) [15] despite the fact that the Libyan population is younger than that of most European countries. Moreover, the incidence rate observed in Libya is even higher than rates reported in other places with young populations such as Qatar (202 pmp) [16], Tunisia (159 pmp) [17],

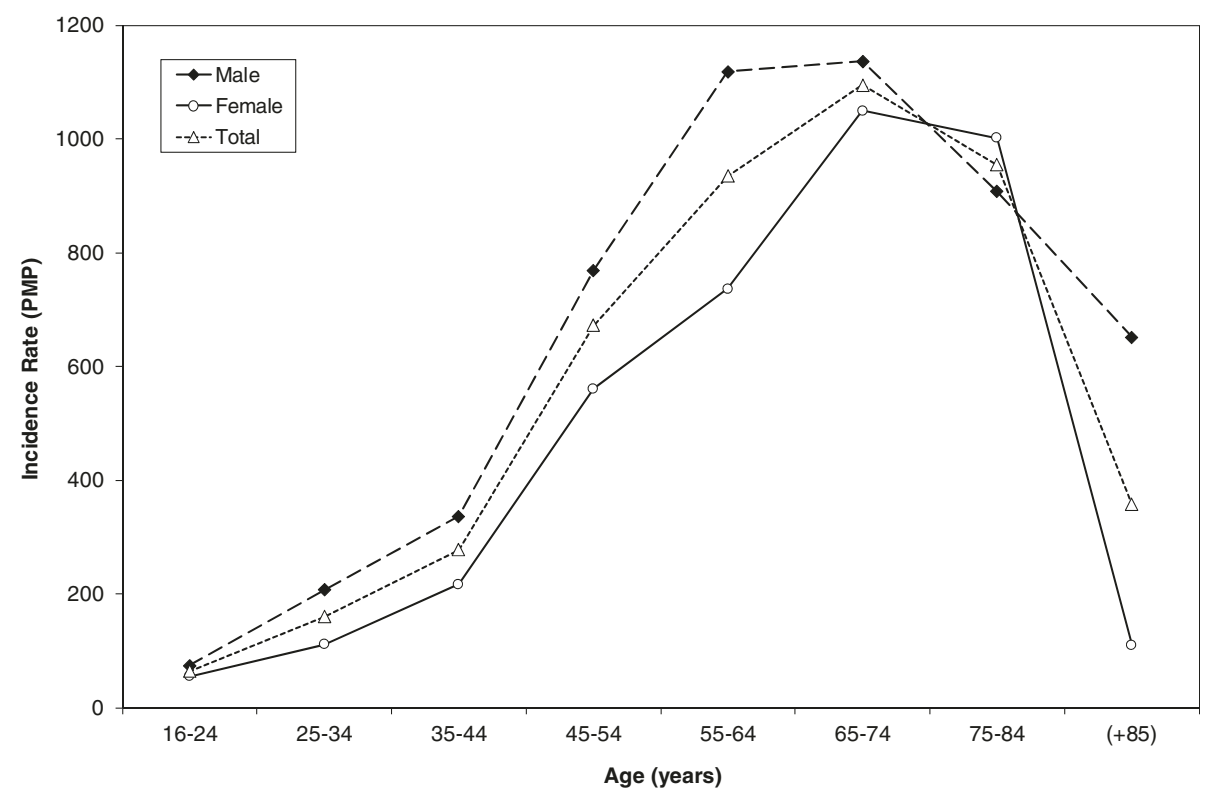

Figure 2 Incidence rate pmp of dialysis-treated ESKD in Libya for males and females by age group. 
Table 3 Aetiology of primary kidney disease of prevalent dialysis patients according to gender and age

\begin{tabular}{|c|c|c|c|c|c|}
\hline \multirow[t]{2}{*}{ Primary kidney disease } & \multicolumn{2}{|c|}{ Gender } & \multicolumn{2}{|c|}{ Age } & \multirow{2}{*}{$\frac{\text { All patients }}{(n=2417)}$} \\
\hline & Male $(n=1402)$ & Female $(n=1015)$ & $<50$ years $(n=1268)$ & $\geq 50$ years $(n=1149)$ & \\
\hline Diabetic Nephropathy & $396(28.2)^{*}$ & $245(24.1)$ & $169(13.3)^{*}$ & $472(41.1)$ & $641(26.5)$ \\
\hline Hypertensive Nephropathy & $180(12.8) *$ & $173(17)$ & $129(10.2)^{*}$ & $224(19.5)$ & $353(14.6)$ \\
\hline Glomerulonephritis & $318(22.7) *$ & $194(19.1)$ & $413(32.6)^{*}$ & $99(8.6)$ & $512(21.2)$ \\
\hline Interstitial Nephritis & $14(1)$ & $15(1.5)$ & $17(1.3)$ & $12(1)$ & $29(1.2)$ \\
\hline Obstructive Nephritis & $78(5.6)$ & $42(4.1)$ & $59(4.7)$ & $61(5.3)$ & $120(5)$ \\
\hline Chronic pyelonephritis & $19(1.4) *$ & $29(2.9)$ & $33(2.6) *$ & $15(1.3)$ & $48(2)$ \\
\hline Polycystic kidney disease & $82(5.8)$ & $70(6.9)$ & $68(5.4)$ & $84(7.3)$ & $152(6.3)$ \\
\hline Congenital and hereditary diseases & $168(12) *$ & $130(12.8)$ & $220(17.3)^{*}$ & $78(6.8)$ & $298(12.3)$ \\
\hline Autoimmune diseases & $4(0.3) *$ & $13(1.3)$ & $16(1.3) *$ & $1(0.1)$ & $17(0.7)$ \\
\hline Other & $39(2.8)$ & $32(3.2)$ & $48(3.8) *$ & $23(2)$ & $71(2.9)$ \\
\hline Unknown & $104(7.4)$ & $72(7.1)$ & $96(7.6)$ & $80(7)$ & $176(7.3)$ \\
\hline
\end{tabular}

Data are number (percent).

${ }^{*} \mathrm{P}<0.05$ versus comparitor group.

Bhopal city in India (151 pmp) [18], Malaysia (138 pmp) [19], Saudi Arabia (122 pmp) [12], Jordan (111 pmp) [20] and Aleppo city in Syria (60 pmp) [21]. Whereas the prevalence rate did not vary by much in the different geographic regions of Libya the observed incidence rate was substantially higher in the South. Regional variation in incidence of ESKD has been reported by other authors $[22,23]$. The reasons for this variation in Libya require further investigation and have important implications for future healthcare provision. The South of Libya is a remote, sparsely populated and deprived area. It is also hot and dry and is inhabited by a mixture of different minorities such as black Arabs, Tuareg and Tebou tribes. Thus geographic, racial and socioeconomic factors may all be relevant. It is also notable that the proportion of new patients who commenced dialysis therapy in one year represents $45 \%$ of the number of prevalent dialysis patients in Libya. Moreover in the
South the incidence rate was triple the prevalence rate. Possible explanations for these observations include a high mortality rate on dialysis or rapidly increasing incidence of ESKD. Both possibilities require urgent investigation and have serious implications for future demand for dialysis in Libya.

The median age of prevalent patients revealed by this study was substantially lower than that observed in other countries including the UK (65.9 years for haemodialysis and 61.2 years for peritoneal dialysis) [24], USA (59.1 years) [25], Iceland (64.4 years), Austria (60.1 years), Denmark (58.8 years) and Greece (58.1 years) [15]. The majority of patients with ESKD in Libya are of economically active age and ESKD therefore has a significant impact on families and society. The observed median age for incident patients in Libya (49 years) was considerably lower than the UK (64.8 years) [26]. Consistent with studies from most other countries, males outnumbered

Table 4 Aetiology of primary kidney disease of incident dialysis patients according to gender and age

\begin{tabular}{|c|c|c|c|c|c|}
\hline \multirow[t]{2}{*}{ Primary Kidney Disease } & \multicolumn{2}{|c|}{ Gender } & \multicolumn{2}{|c|}{ Age } & \multirow{2}{*}{$\begin{array}{l}\text { All patient } \\
(n=1018)\end{array}$} \\
\hline & Male $(n=621)$ & Female $(n=397)$ & $<50$ years $(n=521)$ & $\geq 50$ years $(n=497)$ & \\
\hline Diabetic Nephropathy & $173(27.9)$ & $116(29.2)$ & $90(17.3)^{*}$ & $199(40)$ & $289(28.4)$ \\
\hline Hypertensive Nephropathy & $101(16.3)$ & $60(15.1)$ & $29(5.6)^{*}$ & $132(26.6)$ & $161(15.8)$ \\
\hline Glomerulonephritis & $133(21.4)$ & $71(17.9)$ & $173(33.2)^{*}$ & $31(6.2)$ & $204(20)$ \\
\hline Interstitial Nephritis & $7(1.1)^{*}$ & $17(4.3)$ & $14(2.7)$ & $10(2)$ & $24(2.4)$ \\
\hline Obstructive Nephritis & $53(8.5)^{*}$ & $6(1.5)$ & $17(3.3)^{*}$ & $42(8.5)$ & $59(5.8)$ \\
\hline Chronic pyelonephritis & $9(1.4)$ & $4(1)$ & $0(0)^{*}$ & $13(2.6)$ & $13(1.3)$ \\
\hline Polycystic kidney disease & $13(2.1)^{*}$ & $41(10.3)$ & $31(6)$ & $23(4.6)$ & $54(5.3)$ \\
\hline Congenital and hereditary diseases & $42(6.8)$ & $40(10.1)$ & $73(14)^{*}$ & $9(1.8)$ & $82(8.1)$ \\
\hline Autoimmune diseases & $4(0.6)^{*}$ & $10(2.5)$ & $11(2.1)^{*}$ & $3(0.6)$ & $14(1.4)$ \\
\hline Other & $10(1.6)$ & $4(1)$ & $10(1.9)$ & $4(0.8)$ & $14(1.4)$ \\
\hline Unknown & $76(12.2)^{*}$ & $28(7.1)$ & $73(14)^{*}$ & $31(6.2)$ & $104(10.2)$ \\
\hline
\end{tabular}

Data are number (percent).

${ }^{*} \mathrm{P}<0.05$ versus comparitor group. 
females in the prevalent and incident populations $[25,27,28]$. Nevertheless, the median age of incident females in the South was a decade younger than females in other regions of the country. This wide range of age presentation in the South might reflect gender inequity, health care deficiency and environmental factors.

Like many other countries diabetic nephropathy was the leading causes of ESKD in both prevalent and incident dialysis populations and was significantly more common among older patients. Generally, the prevalence of diabetes in Middle East region is high according to the International Diabetes Federation [29,30]. Reasons include increasing urbanisation, aging of the population, increasing obesity and falling levels of physical activity $[31,32]$. Efforts to reduce the burden of ESKD in Libya should therefore focus on measures to reduce incidence of type 2 diabetes mellitus [33,34] through public awareness, screening and promotion of a healthy lifestyle as well as prevention of microvascular complications in those with diabetes [35]. Glomerulonephritis was the second most frequent cause of ESKD in Libya in prevalent and incident cases and was significantly more common among young and male patients. The observed proportion is midway between very high levels reported from countries like China and Kuwait of approximately 35\% [36,37], Costa Rica (30\%) [38] and Yemen (25\%) [39] and lower prevalence observed in countries like Qatar (13\%) [16], Sri Lanka (12\%) [40] and Pakistan (10\%) [41]. Reasons for the high prevalence of glomerulonephritis require further investigation, which is hampered by the shortage of facilities able to perform renal biopsies and histology. A substantial proportion of ESKD was attributed to hypertension but it is unclear what proportion of this represented hypertension secondary to primary renal disease. Congenital and hereditary kidney disease accounted for a significant minority of ESKD in both prevalent and incident patients. This is likely due to the high rate of marriages between relatives, especially first cousins, in Arab communities [42-44] including Libya. A shortage of genetic diagnostics and counselling is a major contributor to this problem. In summary, despite Libya's unique social and demographic features the observed causes of ESKD are similar to that described in most other countries, though the contribution of glomerulonephritis and hereditary kidney disease is greater than in many developed countries. It is therefore likely that interventions that have proved successful in reducing the incidence of ESKD in other countries such as early detection of CKD, treatment of hypertension with angiotensin-converting enzyme inhibitors and prevention or treatment of diabetes are likely to be effective in Libya too.

Strengths of this study are the inclusion of all current dialysis units in the country to ensure collection of the most complete data possible and prospective capture of data regarding new patients commencing dialysis. Limitations include reliance on limited and partially incomplete medical records and lack of histology to confirm the cause of ESKD in the majority of cases. We have described the epidemiology of ESKD among patients receiving dialysis but there are no data regarding patients with ESKD who died without the benefit of dialysis. It is therefore likely that the true incidence of ESKD is higher than what we have observed. Further research is required to investigate how many patients with ESKD are not offered dialysis and the reasons for this.

\section{Conclusions}

In conclusion we report for the first time high prevalence and incidence rates of dialysis-treated ESKD in Libya. The relatively young age of those affected emphasizes the need for urgent measures to reduce the incidence of CKD and its progression. Emphasis should be placed in the first instance on the prevention and treatment of diabetes and hypertension. Further research is required to investigate the high incidence of glomerulonephritis. As Libya rebuilds its healthcare system following the recent conflict it is hoped that the prevention of ESKD will constitute an important priority and that the data presented will inform the strategies required.

\section{Methods}

The study was performed by a Libyan researcher with support and guidance provided by a Nephrology Department in the United Kingdom. First, a cross-sectional study was performed from May to September 2009. This included all adult maintenance dialysis facilities in Libya $(n=39)$, which all belong to the public sector. Medical supervisors of maintenance dialysis facilities throughout the country were contacted by visit or phone call to be informed about the study. All agreed to participate and to cooperate with the research team.

A data collection sheet was prepared and used to gather information about all currently registered dialysis patients in the country. Forms included data regarding date of birth, sex, ethnicity, nationality, type of dialysis, date of dialysis initiation and primary kidney disease. Date of birth was recorded if known. Otherwise, the year of birth was used. The same applied for the date of first dialysis. Primary kidney disease was recorded according to the opinion of the treating physician or medical reports when available.

For the majority of dialysis units $(n=28)$, the research team collected all information by interviewing patients and inspecting medical records to assure quality and validity of the data. For remote facilities, data collection sheets were distributed to the clinical supervisor for completion. Frequent phone calls were used to answer queries and ensure that data were correctly documented. A pilot study was 
undertaken in 5 dialysis units that included 100 patients (20 from each unit). Difficulties in collecting data were explored and solutions developed. Data were cross checked for patients who were known to receiving dialysis in another centre within the country. Patients who were absent at the time of the study for a period of less than one month for travel in or outside the country were included among the prevalent population. Analyses performed included all adult patients prevalent on dialysis on 30 August 2009.

Population estimates were obtained from the Libyan national statistics department. The age and gender breakdown of the population in each region was obtained from mid-2009 population estimates based on 2006 census data. The number of dialysis patients was calculated for the country as a whole. In order to investigate geographic variation in the epidemiology of ESKD, data were also grouped into 3 main geographic regions.

The second stage of the study was a prospective collection of information about all new patients who started dialysis from September 2009 to August 2010. Variables collected were identical to that used during the crosssectional study and the same data forms were used. The research team conducted data collection frequently during the year to ensure the inclusion of every new patient in the country. Subsequently, researchers conducted field visits to dialysis facilities from September to December 2010 to validate the information.

Data are presented as mean \pm standard deviation if normally distributed or median (interquartile range) if not. A Chi-squared test was used to compare frequencies between groups. A p-value of $<0.05$ was considered statistically significant. Analysis was performed by using SPSS version 16.0.

Permission to conduct the study was granted by the Ministry of Health. Ethical approval for the research was obtained from the Libyan National Committee for Bioethics and Bio-safety. Patients each gave written informed consent.

\section{Competing interest}

The authors have no conflicts of interest to declare. The results presented in this paper have not been published previously in whole or part, except in abstract form.

\section{Acknowledgments}

The authors would like to thank the Libyan National Authority for Scientific Research (NASR) and the teaching and research staff in the Department of Community Medicine in Tripoli University for invaluable assistance in gathering data as well as healthcare teams and patients in Libyan dialysis facilities for their cooperation.

\section{Author details}

${ }^{1}$ School of Graduate Entry Medicine, University of Nottingham, Nottingham, UK. ${ }^{2}$ Department of Renal Medicine, Derby Hospitals NHS Foundation Trust, Derby, UK. ${ }^{3}$ Royal Derby Hospital, Uttoxeter Road, Derby DE22 3NE, UK.

\section{Authors' contributions}

The contribution of each of the authors was as follows: WA: study design, collection of all data, analysis of data, writing of manuscript. CWM: study design, review of data, writing and revision of manuscript. MWT: study design, review of data, writing and revision of manuscript. All authors read and approved the final manuscript.

\section{Authors' information}

WA is based in Libya and conducted this study as part of a PhD project, supervised by CWM and MWT, who are consultant nephrologists in the UK.

Received: 15 December 2011 Accepted: 8 June 2012

Published: 8 June 2012

\section{References}

1. Rao GM: Diabetes mellitus in Libya: a retrospective study. Indian J Med SCi 1992, 46(6):174-181.

2. The National Board for Scientific Research T-L: Risk factors for hypertension., Volume 3; 2001:32-39.

3. Roaeid RB, Kablan AA: Diabetes mortality and causes of death in Benghazi: a 5-year retrospective analysis of death certificates. East Mediterr Health J 2010, 16(1):65-69.

4. Kadiki OA, Roaeid RB: Prevalence of diabetes mellitus and impaired glucose tolerance in Benghazi Libya. Diabetes Metab 2001, 27(6):647-654.

5. WHO: Eastern Mediterranean Regional Health Systems ObservatoryHealth Systems Profile- Libya. WHO: 2007. http://www.emro.who.int. Accessed December 2011.

6. Salam AA, Alshekteria AA, Abd Alhadi H, Ahmed M, Mohammed A: Patient satisfaction with quality of primary health care in Benghazi, Libya. Libyan J Med 2010, 5. doi:10.3402/ljm.v5i0.4873.

7. Alashek WA, Mclntyre CW, Taal MW: Provision and quality of dialysis services in Libya. Hemodial Int 2011, 15(4):444-452.

8. Usta A, Shawish T, Mishra A, Ehtuish EF, Ajaj H, Milud N, Shebani A, Abdulmola T, Tejori U: Living related kidney transplantation in Libya: a single center experience. Transplant Proc 2008, 40(10):3428-3433.

9. Ehtuish EF, Abouna GM, Shebani AH, Abdulmola TS, Shawesh TZ: Kidney transplantation in Libya: a North African and Middle Eastern perspective. Exp Clin Transplant 2006, 4(1):425-428.

10. Abboud O: Incidence, prevalence, and treatment of end-stage renal disease in the Middle East. Ethn Dis 2006, 16 (2 Suppl 2):S2-2-4.

11. Najafi I: Peritoneal dialysis in iran and the middle East. Perit Dial Int 2009, 29(Suppl 2):S217-S221

12. Saudi Centre for Organ Transplantation Annual Report 2009. 2009 http://www.scot.org.sa/Accessed December 2011.

13. El Minshawy O: End-stage renal disease in the El-Minia Governorate, upper Egypt: an epidemiological study. Saudi J Kidney Dis Transp/ 2011 22(5):1048-1054

14. Alashek W, Ehtuish E, Elhabashi A, Emberish W, Mishra A: Reasons for unwillingness of libyans to donate organs after death. Libyan J Med 2009, 4(3):110-113.

15. ERA-EDTA Registry: ERA-EDTA Registry Annual Report 2007. Amsterdam, The Netherlands: Academic Medical Center, Department of Medical Informatics; 2009. http://www.era-edta-reg.org/ Accessed December 2011.

16. Shigidi MM, Ramachandiran G, Rashed AH, Fituri OM: Demographic data and hemodialysis population dynamics in Qatar: a five year survey. Saudi J Kidney Dis Transp/ 2009, 20(3):493-500.

17. Counil E, Cherni N, Kharrat M, Achour A, Trimech H: Trends of incident dialysis patients in Tunisia between 1992 and 2001. Am J Kidney Dis 2008, 51(3):463-470

18. Prabahar MR, Chandrasekaran V, Soundararajan P: Epidemic of chronic kidney disease in India -what can be done? Saudi J Kidney Dis Transpl 2008, 19(5):847-853.

19. Ngo LYOL, Guat LD: 16th Report of the Malaysian Dialysis and Transplant Registry 2008. 2008, http://www.msn.org.my/ Accessed December 2011.

20. Batieha A, Abdallah S, Maghaireh M, Awad Z, Al-Akash N, Batieneh A, Ajlouni KA: Epidemiology and cost of haemodialysis in Jordan. East Mediterr Health J 2007, 13(3):654-663.

21. Moukeh G, Yacoub R, Fahdi F, Rastam S, Albitar S: Epidemiology of hemodialysis patients in Aleppo city. Saudi J Kidney Dis Transpl 2009, 20(1):140-146

22. Mathur AK, Ashby VB, Sands RL, Wolfe RA: Geographic variation in endstage renal disease incidence and access to deceased donor kidney transplantation. Am J Transplant 2010, 10(4 Pt 2):1069-1080. 
23. Wimmer F, Oberaigner W, Kramar R, Mayer G: Regional variability in the incidence of end-stage renal disease: an epidemiological approach. Nephrol Dial Transplant 2003, 18(8):1562-1567.

24. Steenkamp R, Castledine C, Feest T, Fogarty D: UK Renal Registry 13th Annual Report (December 2010): chapter 2: UK RRT Prevalence in 2009: national and centre-specific analyses. Bristol: UK Renal Registry; 2010:35-60.

25. Collins AJ, Foley RN, Herzog C, Chavers B, Gilbertson D, Ishani A, Kasiske B, Liu J, Mau LW, McBean M, et al: United States renal data system 2008 annual data report. Am J Kidney Dis 2009, 53(1 Suppl):S1-S374.

26. Gilg J, Castledine C, Fogarty D, Feest T: UK Renal Registry 13th Annual Report (December 2010): chapter 1: UK RRT Incidence in 2009: national and centre-specific analyses.: UK Renal Registry; 2010:9-33.

27. Goodkin DA, Young EW, Kurokawa K, Prutz KG, Levin NW: Mortality among hemodialysis patients in Europe, Japan, and the United States: case-mix effects. Am J Kidney Dis 2004, 44(5 Suppl 2):16-21.

28. Iseki K, Nakai S, Shinzato T, Nagura Y, Akiba T: Increasing gender difference in the incidence of chronic dialysis therapy in Japan. Ther Apher Dial 2005, 9(5):407-411.

29. Atkins RC: The epidemiology of chronic kidney disease. Kidney Int Supp/ 2005, 94:S14-S18.

30. Wild S, Roglic G, Green A, Sicree R, King H: Global prevalence of diabetes: estimates for the year 2000 and projections for 2030. Diabetes Care 2004, 27(5):1047-1053.

31. Belqacem S: Health issues in the Arab American community. Commentary: the growing risk factors for noncommunicable diseases in the Arab world. Ethn Dis 2007, 17(2 Suppl 3):S3-51-S53-52

32. Khogali M: Health and disease in a changing Arab world 2000/2025/ 2050: global, environmental, and climate change and emerging diseases. Ethn Dis 2005, 15(1 Suppl 1):S1-74-75.

33. Iseki K: Factors influencing the development of end-stage renal disease. Clin Exp Nephrol 2005, 9(1):5-14

34. Farag Y, Al Wakeel J: Diabetic Nephropathy in the Arab Gulf Countries. Nephron Clin Pract 2011, 119(4):C317-c323.

35. Kramer H: Screening for kidney disease in adults with diabetes and prediabetes. Curr Opin Nephrol Hypertens 2005, 14(3):249-252.

36. Zhang AH, Zhong H, Tang W, Chen SY, He L, Wang S, Su CY, Lu XH, Wang $\mathrm{T}$ : Establishing a renal management clinic in China: initiative, challenges, and opportunities. Int Urol Nephrol 2008, 40(4):1053-1058.

37. El-Reshaid W, El-Reshaid K, Kapoor M, Hakim A: Chronic renal disease in Kuwaiti nationals: a prospective study during the past 4 years. Ren Fail 2005, 27(2):227-233.

38. Cerdas M: Chronic kidney disease in Costa Rica. Kidney Int Supp/ 2005, 97:S31-S33.

39. Badheeb AM: Causes of chronic renal failure in hemodialysis unit: a single center experience in Yemen. Saudi J Kidney Dis Transp/ 2006, 17(1):66-69.

40. Gooneratne IK, Ranaweera AK, Liyanarachchi NP, Gunawardane N, Lanerolle RD: Epidemiology of chronic kidney disease in a Sri Lankan population. Int J Diabetes Dev Ctries 2008, 28(2):60-64.

41. Rizvi SA, Manzoor K: Causes of chronic renal failure in pakistan: a single large center experience. Saudi J Kidney Dis Transpl 2002, 13(3):376-379.

42. Teebi AS, Teebi SA, Porter CJ, Cuticchia AJ: Arab genetic disease database (AGDDB): a population-specific clinical and mutation database. Hum Mutat 2002, 19(6):615-621.

43. Barbari A, Stephan A, Masri M, Karam A, Aoun S, El Nahas J, Bou Khalil J: Consanguinity-associated kidney diseases in Lebanon: an epidemiological study. Mol Immunol 2003, 39(17-18):1109-1114.

44. Hoodfar E, Teebi AS: Genetic referrals of Middle Eastern origin in a western city: inbreeding and disease profile. J Med Genet 1996, 33(3):212-215

doi:10.1186/1471-2369-13-33

Cite this article as: Alashek et al.: Epidemiology and aetiology of dialysistreated end-stage kidney disease in Libya. BMC Nephrology 2012 13:33.

\section{Submit your next manuscript to BioMed Central and take full advantage of:}

- Convenient online submission

- Thorough peer review

- No space constraints or color figure charges

- Immediate publication on acceptance

- Inclusion in PubMed, CAS, Scopus and Google Scholar

- Research which is freely available for redistribution

Submit your manuscript at www.biomedcentral.com/submit
() Biomed Central 